\title{
Effects of Measurements Conditions on an Extended-Gate FET used as pH sensor
}

\author{
Jessica Colnaghi Fernandes ${ }^{a} *$ Raphael Aparecido Sanches Nascimento ${ }^{a}$, Marcelo Mulato ${ }^{a}$ \\ ${ }^{a}$ Physics Department, University of São Paulo - USP, Av. Bandeirantes, 3900, Ribeirão Preto, SP, Brazil
}

Received: May 4, 2015; Revised: November 3, 2015; Accepted: December 16, 2015

\begin{abstract}
Fluorine-doped tin oxide $\left(\mathrm{SnO}_{2}: \mathrm{F}\right)$ was investigate as the sensitive part of a $\mathrm{pH}$ sensor in the extended-gate field effect transistors (EGFET) device, which provided a linear response for $\mathrm{pH}$ range from 2 to 12 ; the sensitivity was $37 \mathrm{mV} \cdot \mathrm{pH}^{-1}$ for experiments performed in absence of light. Neutral $\mathrm{pH}$, leads to a transistor's electric current remained practically constant, suggesting that $\mathrm{pH} 7$ correspond to the isoelectric point of the $\mathrm{SnO}_{2}: \mathrm{F}$ samples. For acid and alkaline $\mathrm{pH}$, the power law varied along time and stabilized at about $10 \mathrm{~min}$. UV-vis light did not alter the results. The transistor's electric current increased with the operating temperature increases. Once that small change in the operating conditions can alter the final results, the physical mechanisms underlying the sensing process must be clearly understood. It is essential to monitor transient response and measurements conditions.
\end{abstract}

Keywords: Extended-gate FET, Fluorine-doped tin oxide, pH sensor, Temperature dependence, Time evolution.

\section{Introduction}

The research in sensors applications shows an extensive application and has increased over the past decade ${ }^{1}$. The need to identify and quantify small amounts of specific species has also contributed to the arousing interest in sensors and biosensors ${ }^{2}$ owing to many biological and chemical processes depends on $\mathrm{pH}$ and it could aid in $\mathrm{pH}$ measurement, for example.

Bergveld used a field effect transistor to measure $\mathrm{pH}$ in neurophysiological conditions for the first time in $1970{ }^{3}$. The ion-sensitive field effect transistor (ISFET) is an integrated device consisting of a metal-oxide-semiconductor field-effect-transistor (MOSFET) in which a sensing electrode replaces the gate ${ }^{4}$. This device has been developed to operate as a chemically selective electrode ${ }^{5}$. Compared with conventional $\mathrm{pH}$-sensitive glass electrodes, the chemical sensor offers numerous advantages such as low cost, the possibility of miniaturization, and high input and low output impedance ${ }^{6}$. These devices are very versatile and their use has even been recently reported as wireless gastrointestinal sensor ${ }^{4,7}$. However, ISFET is a device that does not allow the sensitive membrane changes. Bearing research and future technological applications in mind, a good strategy would be to replace ISFET with the extended-gate field-effect-transistor (EGFET), due to its possibility to isolate the sensitive layer from the electronic components. In EGFET, a conducting wire connects a commercial MOSFET to a sensitive layer ${ }^{8}$, and it is easy to replace the sensitive layer. Moreover, it is feasible to alter the measurement conditions without modifying the MOSFET conditions, as the light exposure of the extended gate and the temperature of the sensing film as well.

EGFET can be used as a pH sensor to detect and quantify a big kind of substances that can produce or consume protons,

*e-mail: jessicacf@pg.ffclrp.usp.br such as enzymes, which could open up a wide range of EGFET applications as biosensors ${ }^{9}$. Researchers have tested and characterized a number of materials to use as ion-sensing film in EGFETs; for example, zinc oxide $(\mathrm{ZnO}){ }^{10}$, tin oxide $\left(\mathrm{SnO}_{2}\right)^{11}$, titanium oxide $\left(\mathrm{TiO}_{2}\right)^{12}$, fluorine-doped tin oxide $\left(\mathrm{SnO}_{2}: \mathrm{F}\right)^{13}$, tantalum pentoxide $\left(\mathrm{Ta}_{2} \mathrm{O}_{5}\right)^{14}$, and mixed oxides like vanadium oxide/hexadecylamine ${ }^{15}$, and pentoxide vanadium/ titanium oxide $\left(\mathrm{V}_{2} \mathrm{O}_{5} / \mathrm{TiO}_{2}\right)^{16}$, among others.

Tin oxide $\left(\mathrm{SnO}_{2}\right)$ is one of the most important transparent conductive oxide (TCO) materials ${ }^{17}$. It exhibits high electrical conductivity and optical transmittance in the UV-vis region ${ }^{18}$, can resist to high temperatures ${ }^{19}$, and presents high IR reflectance ${ }^{17}$. Doping helps to refine $\mathrm{SnO}_{2}$ for TCO applications and the dopants can be fluorine ${ }^{20}$, antimony ${ }^{21}$, indium ${ }^{22}$, and zinc ${ }^{17}$. Previous studies have reported that fluorine and antimony are better dopants for $\mathrm{SnO}_{2}$ films, because they elicit low electrical resistivity and high transmittance for solar cell applications ${ }^{17,23}$. The formation of F-Sn complexes reduces both the concentration and mobility of the carriers ${ }^{18}$, and the dopant considerably affects the reaction process by controlling the $\mathrm{SnO}_{2}$ film growth kinetics ${ }^{24} \cdot \mathrm{SnO}_{2}: \mathrm{F}$ (fluorine doped tin oxide) films are thermally stable, do not depend on oxygen vacancies to provide charge carriers ${ }^{25}$, resist physical abrasion, and display chemical stability, high optical visible transparency, and electrical conductivity ${ }^{26}$. $\mathrm{SnO}_{2}: \mathrm{F}$ is an alternative to indium-doped tin oxide (ITO) when chemical or electrical stability is necessary at elevated temperatures ${ }^{27}$. $\mathrm{SnO}_{2}: \mathrm{F}$ has application in many optoelectronic devices such as the electrodes employed in various types of solar cells ${ }^{28,29}$.

The transient effects of sensors, including ISFETs and EGFETs, and the specific and detailed conditions of devices operation and characterization have been explored less than necessary. Batista et al. grew $\mathrm{SnO}_{2}: \mathrm{F}$ by the sol-gel technique 
and used it in EGFET to obtain a good response as a function of $\mathrm{pH}$ and high sensitivity ${ }^{13}$. However, it is essential to conduct a more detailed study of the transient behavior of the sensor containing this material. The present study used $\mathrm{SnO}_{2}: \mathrm{F}$ films and focused on the transient and operating temperature effects. Measurements with time-evolved results for the $\mathrm{SnO}_{2}: \mathrm{F}$ sensing film in a $\mathrm{pH}$ sensor EGFET device as a function of time, illumination, and operating temperature are discussed.

\section{Materials and Methods}

The $\mathrm{SnO}_{2}: \mathrm{F}$ samples were purchased from Flexitec company. The company fabricated those samples via the spray-pyrolysis technique and they present $512 \mathrm{~nm}$ thickness in average, $10 \mathrm{~mm} \times 23 \mathrm{~mm}$ surface area, and $23 \Omega / \mathrm{sqr}$ sheet resistance. Electric contact was made using a thin copper wire and conductive silver paint on the edge of the sample. The contact was encapsulated with an epoxy resin. Previous studies had reported that silver paint forms ohmic contacts with $\mathrm{SnO}_{2}: \mathrm{F}$ and displays low resistivity, because silver diffuses in the film and increases the number of free charge carriers as compared with other metallic contacts ${ }^{30}$.

The EGFETs were fabricated by connecting the samples to the gate of a commercial MOSFET (CD4007) - Texas Instruments. The samples were dipped in buffer solutions with $\mathrm{pH}$ values ranging from 2 to 12, acquired from CINETICA.

\section{EXPERIMENTAL}

The samples were rinsed with Milli-DI water for $15 \mathrm{~min}$ before each measurement. Milli-DI contains only a small amount of ions. Normally its conductivity lies between 1 and $0.1 \mu \mathrm{S} \bullet \mathrm{cm}^{1}$, so its resistivity is around 1 to $10 \mathrm{M} \Omega \bullet \mathrm{cm}$. The amount of ions that might remain on the film's surface after each cleaning process is much smaller than the amount of ions originated from the buffer solution. Hence, the standardized cleaning process ensures that the charge and the final measurements varies only due to the buffer solution ions interaction with the surface of the film. The minimum amount of ions in the Milli-DI water does not affect the final result.

Figure 1(a) illustrates the experimental setup. A reference silver electrode was connected to the drain of the MOSFET, while its source terminal is grounded. According to the figure, $\mathrm{V}_{\mathrm{Ref}}$ corresponds to the reference electrode voltage, $\mathrm{V}_{\mathrm{ds}}$ is the voltage between the drain and the source, and $\mathrm{V}_{\mathrm{gs}}$ is the voltage between the gate and the source. In fact, $\mathrm{V}_{\mathrm{gs}}$ consist of $\mathrm{V}_{\mathrm{Ref}}$ plus the voltage built up between the solution and the film $(\mathrm{dV})$. The drain-source current $\left(\mathrm{I}_{\mathrm{ds}}\right)$ was measured using an HP Data Acquisition 34970A system. An Agilent E3646A Dual Output DC Power Supply unit was also employed in the set-up.

The measurements were conducted both in the absence of light and under UV-VIS radiation.

For this, a system with 14 ultra bright white LEDs (diameter of $5 \mathrm{~mm}$ ) was connected to a DC FA-3005 Power Supply. The LEDs were operated at $6 \mathrm{~V}(20 \mathrm{~mA})$, at a total distance of about $22 \mathrm{~cm}$ from the films, with irradiance of 6.7 Wb. $\mathrm{m}^{-2}$ over the sample. The entire apparatus shown in Figure 1(a) was kept inside a dark box together with the LEDs system. For experiments in presence of light the LEDs

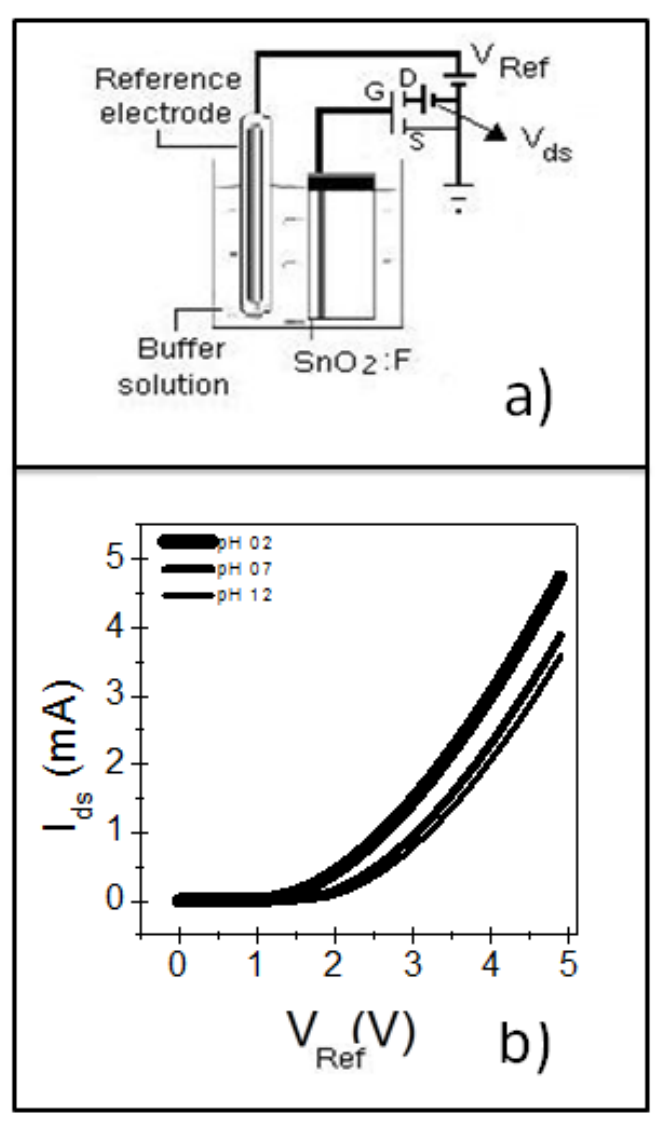

Fig. 1. (a) EGFET measurement system, and (b) typical $I_{d s} \times V_{\text {REF }}$ curve for different $\mathrm{pHs}$.

were turned on, and for experiments in the dark the LEDs were kept switched off.

For the experiments as a function of operating temperature, a thermostat was kept inside the buffer solution with the sensing film and the reference electrode. The complete apparatus (the same shown in Figure 1(a)) was partially immersed in a beaker with water and a magnetic stirrer. Data were only acquired after the temperature of the buffer solution was stabilized. All measurements were performed inside the control box.

Figure 1(b) shows typical $I_{d s} \times V_{\text {REF }}$ curves. Measurements were accomplished by varying the gate-source voltage while keeping $\mathrm{V}_{\mathrm{ds}}$ fixed. The sensitivity of the device is determined by using fixed $I_{d s}$ values ${ }^{31,32}$. This measurement was referred to as the $\mathrm{V}_{\mathrm{gs}}$ setup.

This kind of device can lead to many possible sensor configurations and operation conditions, because $\mathrm{I}_{\mathrm{ds}}$ depends on the $\mathrm{pH}$ of the buffer solution (Figure 1(b)). The response of the devices were investigated using time evolution, light absence or its presence and as a function of the operating temperature.

This paper proposes the standardization of the results to facilitate the experiments reproduction and thereby increases the success of new sensors production. Unfortunately, there is no results in literature to compare with the data acquired in this paper. 


\section{Results and Discussion}

Figure 2 shows the scanning electron microscopy (SEM) image of an original $\mathrm{SnO}_{2}: \mathrm{F}$ sample. Figure 2(a) shows that the surface is very rough and porous, with submicrometric grains, leading to a total exposed surface area greater than the conventional geometric area. Figure 2(b) shows that the $\mathrm{SnO}_{2}: \mathrm{F}$ sample is about $500 \mathrm{~nm}$ thick, and that the submicrometric grains have a columnar structure.

Figure 3 shows the $I_{d s}$ time evolution for different buffer solutions, measured in the absence of light. Both $\mathrm{V}_{\mathrm{ds}}$ and $\mathrm{V}_{\text {Ref }}$ were kept constant. The current depends on the buffer solution $\mathrm{pH}$. Increasing $\mathrm{pH}$ (i.e., lower $\mathrm{H}^{+}$concentration in the solution) elicits smaller currents. Water molecules in the solution attach to the sample surface, generating free sites to which $\mathrm{H}^{+}$ions can bind. This will generate $\mathrm{H}_{3} \mathrm{O}^{+}$ions and the typical double layer of the Helmholtz plane ${ }^{33}$, followed by the Gouy-Chapman region, where charge diffusion extends to the solution bulk. These two regions determine or even modulate the potential gradient across the solution, leading to varied currents. The higher the amount of $\mathrm{H}^{+}$ions in the solution the thicker the Gouy-Chapman region, and the faster the Gouy-Chapman region is formed, leading to larger current values. The focus was on the surface/electrolyte interface ${ }^{34}$.

The time evolution of the electric current heavily depends on $\mathrm{pH}$ values and presents distinct behavior in acid, neutral, and alkaline solutions. The isoelectric point, or point of zero charge (PZC), is the point where the electrical charge density on a surface is zero. Depending on the electrolyte $\mathrm{pH}$, the $\mathrm{SnO}_{2}: \mathrm{F}$ surface can be neutral, positively or negatively charged $^{35-37}$.

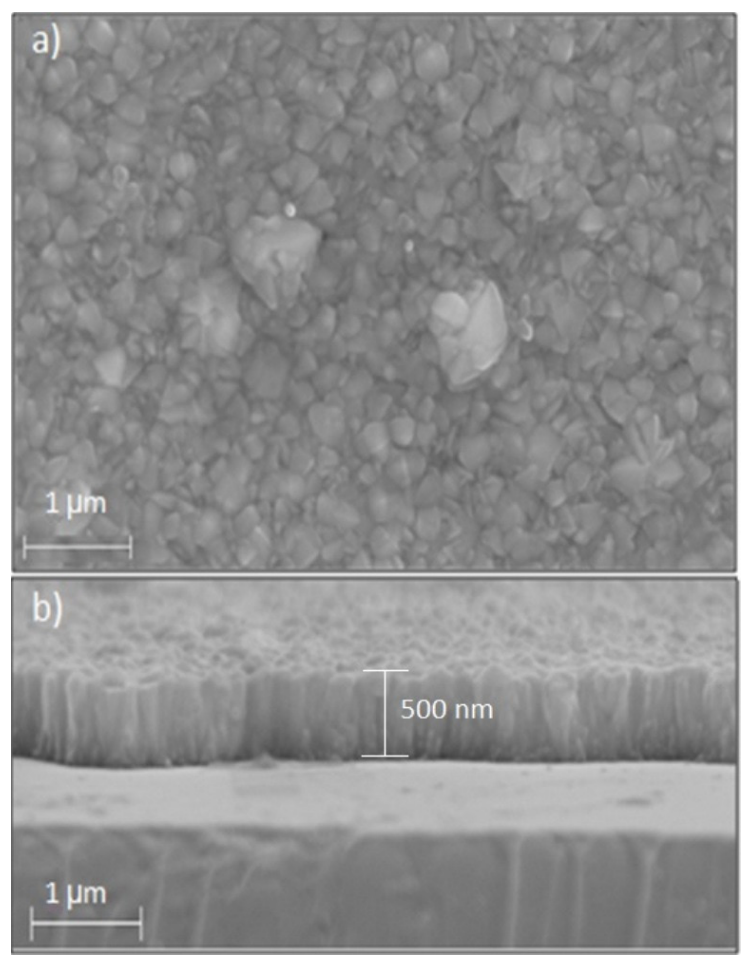

Fig. 2. Scanning electron microscopy (SEM) studies of the starting $\mathrm{SnO}_{2}$ :F sensing film: (a) Surface and (b) tilted cross section.
The surface potential $(\psi)$ between the sensitive layer and the electrolyte interface depends on the PZC according to the site-binding model ${ }^{38}$ :

$\psi=2.303 \frac{k T}{q} \frac{\beta}{\beta+1}(P Z C-p H)$

$\mathrm{T}$ is the absolute temperature, $\mathrm{k}$ is the Boltzmann constant, $\mathrm{q}$ is the electron charge, and $\beta$ is the sensitivity factor.

When the $\mathrm{pH}$ of the solution is lower than the PZC, the hydroxide species on the surface of the film are mostly protonated, to give $-\mathrm{OH}_{2}^{+}$. This elicits a positive net charge on the surface ${ }^{39,40}$.

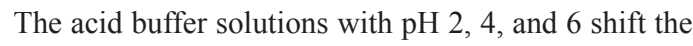
reaction equilibrium toward hydronium ions formation, so the surface of the film becomes positively charged. Further stabilization follows a power law decay (Figure 3(a)). The most marked reduction occurs within the first minute. As the free sites on the surface of the film acquired a positive charge due to the presence of hydronium ions from the solution, the double layer and the Gouy-Chapman region arise rapidly, and the current decreases until stabilization. The same behavior applies to other acid $\mathrm{pH}$ values, like $\mathrm{pH} 4$ and 6 (not shown in Fig. 3), but increasing $\mathrm{pH}$ values culminate in smaller amplitudes.

At pH 7, the current varies little with time (see Figure 3(b)), suggesting that this $\mathrm{pH}$ corresponds to the isoelectric point of the $\mathrm{SnO}_{2}: \mathrm{F}$ samples.

When the solution $\mathrm{pH}$ is larger than the PZC, most of the hydroxide species on the film surface will be deprotonated, to form $-\mathrm{O}^{-}$, providing a negatively charged surface ${ }^{40,41}$. The power law rises (Figure 3(c)). The time constant for

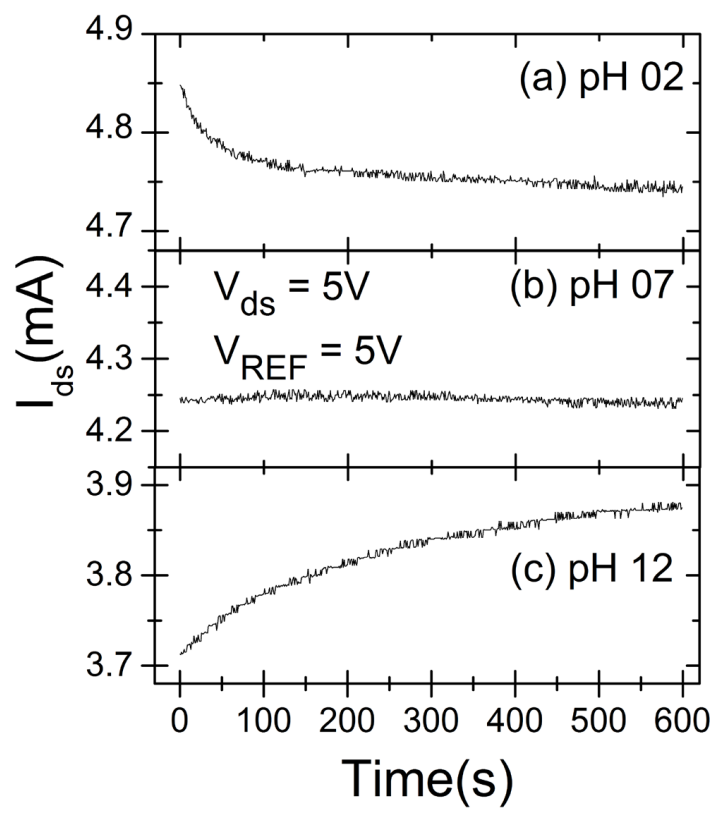

Fig. 3. Time evolution of the EGFET electric current for varied solution $\mathrm{pH}$ values: (a) $\mathrm{pH}$ 02, (b) $\mathrm{pH}$ 07, and (c) $\mathrm{pH} 12$. 
alkaline solutions is much larger as compared with that of acid solutions. The same behavior holds for other alkaline $\mathrm{pH}$ values, such as $\mathrm{pH} 8$ and 10 (not shown in the figure).

The buffer solutions with $\mathrm{pH} 8,10$, and 12 shift the process equilibrium toward the formation of negative ions, so the surface of the film is negatively charged. A solution with alkaline $\mathrm{pH}$ does not rely on a large supply of $\mathrm{H}^{+}$ions; hence the double layer and the Gouy-Chapman region take longer to form as compared with the situation in acid $\mathrm{pH}$. This results from the lower mobility of negative ions in relation to hydronium and from a smaller availability of positive species. Double-layer generation depends on complex ion interactions, charge movement (such as the competition between ion diffusion and drift), changes in the electric field inside the solution, and chemical equilibrium in the buffer solutions ${ }^{42}$. Together, these facts account for the current temporal evolution profile.

To better visualize the total current variation for each $\mathrm{pH}$ along $10 \mathrm{~min}$, the absolute value of the difference $\left(\Delta \mathrm{I}_{\mathrm{ds}}\right)$ between the initial $\left(\mathrm{I}_{\mathrm{ds} 0}\right)$ and the final $\left(\mathrm{I}_{\mathrm{ds} 600}\right)$ currents from Figure 3 were divided by the respective initial values. The new $\Delta \mathrm{I}_{\mathrm{ds}} / \mathrm{I}_{\mathrm{ds} 0}$ variable was plotted as a function of $\mathrm{pH}$ in Figure 4. The solid squares in the figure correspond to the experiments performed in the absence of light.

According to the data in Figure 4, the total current varies slightly less for acid solutions as compared to alkaline solutions, as discussed in Figure 3. The maximum current variation for each $\mathrm{pH}$ value corresponds to less than $5 \%$. The total current variation (considering the initial values only) between $\mathrm{pH} 2$ and 12 is about $30 \%$. In other words, the current variation along time is smaller than the maximum interval of initial currents between $\mathrm{pHs} 2$ and 12. Figure 4 shows that the current does not vary at $\mathrm{pH}$ 7. As previously discussed, this might correspond to the isoelectric point of the $\mathrm{SnO}_{2}: \mathrm{F}$ film, where no variation should occurs.

Data from experiments involving sample irradiated with UV-vis light during the measurement were also collected. Figure 4 shows the results in the presence of light as open circles. A previous study showed that exposure to light could affect EGFET sensitivity ${ }^{42}$.In this work, the data do not vary significantly as compared with the previous case; i.e., less than $0.5 \%$. The sensitivities are close too, indicating no effect from light. Note that the sensitivity obtained for the experiments accomplished in the absence of light was $37 \mathrm{mV} \cdot \mathrm{pH}^{-1}$. The estimated uncertainty is about $10 \%$. The samples assayed in the presence of light display sensitivity of $34 \mathrm{mV} \cdot \mathrm{pH}^{-1}$. Both results do not reach the highest possible theoretical sensitivity of $59.2 \mathrm{mV} \cdot \mathrm{pH}^{-1}$ predicted by the Nernstian law ${ }^{43}$. Nevertheless, we believe that this fact does not jeopardize the actual findings.

Many authors have reported on new sensor properties, but few have provided information about current evolution along time. This prevents the comparison between independent research works, and future applications might not be directly practicable. Either instantaneous or stabilized situation during sensor's operation might be used, but the specific condition must be clearly stated. In addition, conducting measurements in the presence or absence of light might impact the final results, even though the present data do not differ significantly.
Another important parameter to be investigated is the operating temperature, considering both the solution and the sensing part of the EGFET at thermal equilibrium. Resistivity is a temperature-dependent variable: higher solution temperatures should reduce the resistivity of the semiconducting material. Figure 5 presents the relevant results for three $\mathrm{pH}$ values $(2,7$, and 12$)$. The operating temperature used for these buffer solutions varied from 25 to $60^{\circ} \mathrm{C}$, in steps of $5^{\circ} \mathrm{C}$. The current rises with temperature increases in all cases.

Both ion mobility in the solution and ion adsorption at the $\mathrm{SnO}_{2}: \mathrm{F}$ film surface depend on the temperature of the system ${ }^{44}$. Ion mobility should be a function of increasing temperature in the studied temperature range. On the other hand, adsorption onto the film surface usually decreases with temperature. For the $\mathrm{V}_{\mathrm{gs}}$ setup, changes in the MOSFET final current originate mainly from $\mathrm{dV}$ variation (that builds up above $\mathrm{V}_{\mathrm{REF}}$ to compose the final $\mathrm{V}_{\mathrm{gs}}$ ). The $\mathrm{I}_{\mathrm{ds} 0}$ values in Figure 5 are extracted from the original data (as plotted in Figure 1(b)) when $\mathrm{V}_{\mathrm{ds}}$ and $\mathrm{V}_{\mathrm{REF}}$ are both fixed at $5 \mathrm{~V}$; i.e., the system variation is associated with the final $\mathrm{dV}$. The maximum current variation is about $5 \%$. Normally, increasing electric

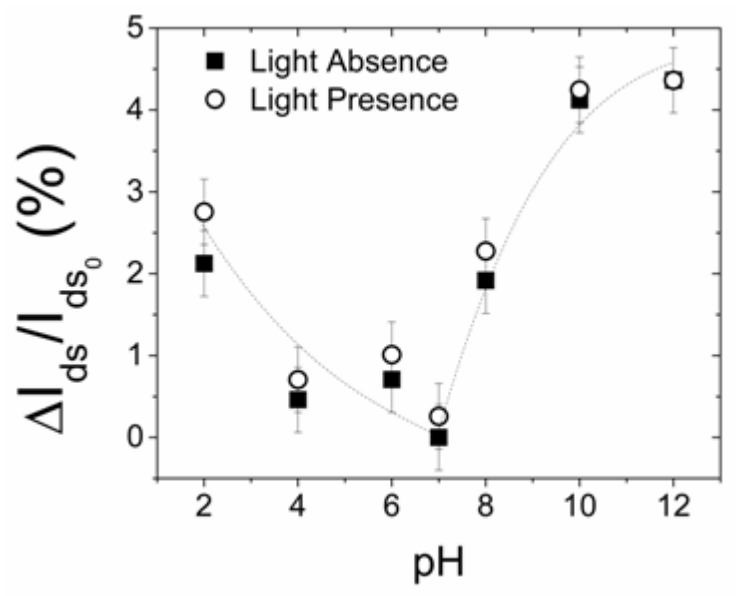

Fig. 4. Percent current variation $\left(\Delta \mathrm{I}_{\mathrm{ds}} / \mathrm{I}_{\mathrm{ds} 0}\right)$ as a function of $\mathrm{pH}$, in presence and in the absence of illumination.

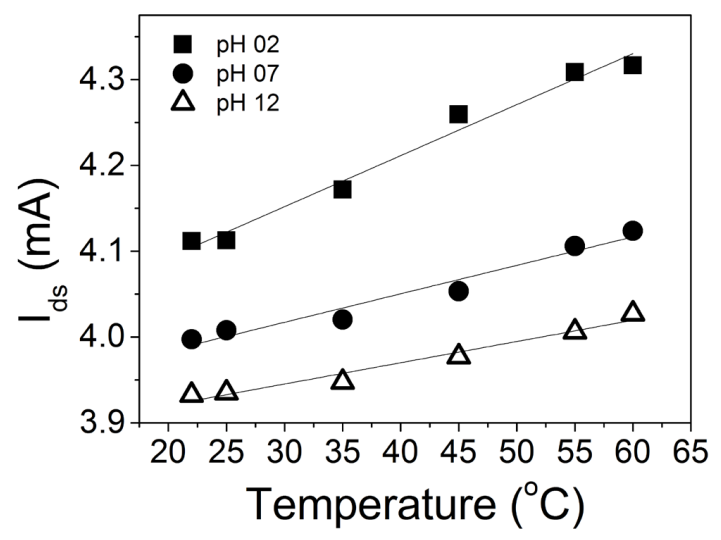

Fig. 5. Drain-source current as a function of operating temperature for three different $\mathrm{pHs} 2,7$ and 12 . 
fields and higher temperatures enhance mobility, causing larger charge separation in the system. Higher electric fields arise between the reference electrode and the sensing film, which culminates in larger $\mathrm{dV}$ values. Indeed, the slopes in Figure 5 are pronounced, especially for lower $\mathrm{pH}$, probably because the availability and mobility of the positive (lighter) and negative (heavier) species inside the solution varies. The possible reduction in ion adsorption does not seem to play a significant role in this temperature range, since the sensitivity increased $60 \%$ at the highest temperature. Hence, it is very important to describe the solution temperature when comparing different sensors in the literature. This is important not only for characterization but also for the eventual final technological application of the device.

\section{Conclusions}

The $\mathrm{I}_{\mathrm{ds}}$ time evolution depends on the solution $\mathrm{pH}$ value. For acid $\mathrm{pH}$, stabilization follows a power law decay. In the case of alkaline $\mathrm{pH}$, saturation follows a power law rise. The current varies by a total of almost $30 \%$ from $\mathrm{pH} 2$ to 12 , but maximum current variation as a function of time is less than $5 \%$ at a certain $\mathrm{pH}$ value. The percentage of current

\section{References}

1. Kao CH, Chen H, Kuo LT, Wang JC, Chen YT, Chu YC, et al. Multi-analyte biosensors on a CF4 plasma treated Nb2O5based membrane with an extended gate field effect transistor structure. Sensors and Actuators B: Chemical. 2014;194:419426. doi:10.1016/j.snb.2013.12.056

2. Thevenot DR, Toth K, Durst RA, Wilson GS. Electrochemical biosensors: recommended definitions and classifications. Biosens Bioelectron. 2001;16(1-2):121131.

3. Bergveld P. Development of an ions-sensitive solid-state device for neurophysiologica measurements. IEEE Transactions on Biomedical Enginering. 1970;17(1):70-71. DOI: 10.1109/ TBME.1970.4502688

4. Xu F, Yan G, Wang Z, Jian P. Continuous accurate $p H$ measurements of human GI tract using a digital pH-ISFET sensor inside a wireless capsule. Measurement. 2015;64:49-56. doi:10.1016/j.measurement.2014.12.044

5. Yin L-T, Chou J-C, Chung W-Y, Sun T-P, Hsiung S-K. Study of indium tin oxide thin film for separative extended gate ISFET. Materials Chemistry and Physics. 2001;70(1): 12-16. doi:10.1016/S0254-0584(00)00373-4

6. Sasaki Y, Kawarada H. Low drift and small hysteresis characteristics of diamond electrolyte-solution-gate FET. Journal of Physics D: Applied Physics. 2010;43(37): 374020.

7. Xu F, Yan G, Zhao K, Lu L, Gao J, Liu G. A wireless capsule system with ASIC for monitoring the physiological signals of the human gastrointestinal tract. IEEE Transactions on Biomedical Circuits Systems. 2014;8(6):871-80. doi: 10.1109/ TBCAS.2013.2296933

8. Batista PD, Mulato M, Graeff CF, Fernandez FJ, Marques FC. $\mathrm{SnO}_{2}$ extended gate field-effect transistor as $\mathrm{pH}$ sensor. Brazilian Journal of Physics. 2006;36(2A):478-482. http:// dx.doi.org/10.1590/S0103-97332006000300066

9. Turek M, Keusgen M, Poghossian A, Mulchandani A, Wang J, Schoning M. Enzymemodified electrolyte-insulator-semiconductor sensors. Journal of Contemporary Physics. 2008;43(2):82-85. variation changes with the $\mathrm{pH}$ value. $\mathrm{UV}$-vis irradiation does not significantly alter the final response as compared with experiments performed in the absence of light. The operating temperature alters the device response. For acid $\mathrm{pH}$, the current value increases more markedly with temperature as compared with alkaline and neutral media. Ion mobility plays a more crucial role than ion adsorption at temperatures below $60^{\circ} \mathrm{C}$. The sensitivity increases about $60 \%$ when the operating temperature was about $60^{\circ} \mathrm{C}$. In summary, for $\mathrm{SnO}_{2}$ :F EGFETs, both the time elapsed during the measurement and the operating temperature can substantially modify the system's response. This study reinforces the importance of monitoring transient responses and of always describing the measurement conditions in novel studies that develop sensors and biosensors. The contribution is propose the results standardization, with more details, due to small operating changes can lead to different conclusions, as showed. With that, new sensors and biosensors can be developed.

\section{ACKNOWLEDGMENT}

The study was supported by FAPESP, CAPES, and CNPq Brazilian agencies.

10. Batista PD, Mulato M. ZnO extended-gate field-effect transistors as pH sensors. Applied Physics Letters. 2005;87:143508. http:// dx.doi.org/10.1063/1.2084319

11. Chou J C, Wang YF. Preparation and study on the drift and hysteresis properties of the tin oxide gate ISFET by the sol-gel method. Sensors and Actuatros B: Chemical. 2002;86(1):58-62. DOI: http://dx.doi.org/10.1016/S0925-4005(02)00147-8

12. Zhao R, Xu M, Wang J, Chen G. A pH sensor based on the TiO nanotube array modified Ti electrode. Electrochimica Acta. 2010;55:5647-5651. DOI: 10.1016/j.electacta.2010.04.102

13. Batista PD, Mulato M. Polycrystalline fluorine-doped tin oxide as sensoring thin film in EGFET pH sensor. Journal of Materials Science. 2010;45:5478-4571.

14. Matsuo T, Esashi M. Methods of ISFET fabrication. Sensors and Actuators. 1981;1:7796. doi:10.1016/0250-6874(81)80006-6

15. Guerra EM, Ciuffi KJ, Oliveira HP. V2O5 xerogel-poly(ethylene oxide) hybrid material: synthesis, characterization, and electrochemical properties. Journal of Solid State Chemistry. 2006;179(12):3814-3823. doi:10.1016/j.jssc.2006.08.018

16. Guerra EM, Silva GR, Mulato M. Extended gate field effect transistor using $\mathrm{V}_{2} \mathrm{O}_{5}$ xerogel sensing membrane by sol-gel method. Solid State Science. 2009;11:456-460. DOI: 10.1016/j. solidstatesciences.2008.07.014

17. Vijayalaksmi S, Venkataraj S, Subramanian M, Jayavel R. Physical properties of zinc doped tin oxide films prepared by spray pyrolysis technique. Journal of Physcis D: Applied Physics. 2008;41(3):3550.

18. Martínez AI, Huerta L, Rueda de LeónJM, Acosta D, Malik O, Aguilar M. Physicochemical characteristics of fluorine doped tin oxide films. Journal of Physics D: Applied Physics. 2006;39(23):5091-5096.

19. Chacko S, Bushiri MJ, Vaidyan VK. Photoluminescence studies of spray pyrolytically grown nanostrucutres tin oxide semiconductor thin films on glass substrates. Journal of Physics D:Applied Physics. 2006;39(21):4540-4543.

20. Shanthi S, Anuratha H, Subramanian C, Ramasamy P. Effect of fluorine doping on structural, electrical and optical properties 
of sprayed $\mathrm{SnO}_{2}$ thin films. Journal of Crystal Growth. 1998;194(3):369-373. DOI: 10.1016/S0022-0248(98)00786-6

21. Rizzato AP, Santilli CV, Pulcinelli SH, Craievich AF. Structural characterization of undoped and Sb-doped $\mathrm{SnO}_{2}$ thin films fired at different temperatures. Journal of Applied Crystal. 2003;36:736-739. doi:10.1107/S0021889803004953

22. Ji Z, He Z, Song Y, Liu K, Ye Z. Fabrication and characterization of indium-doped ptype $\mathrm{SnO} 2$ thin films. Journal of Crystal Growth. 2003;259:282-258. doi:10.1016/j.jcrysgro.2003.07.003

23. Thangaraju B. Structural and electrical studies on highly conducting spray deposited fluorine and antimony doped $\mathrm{SnO}_{2}$ thin films from $\mathrm{SnCl}_{2}$ precursor. Thin Solid Films. 2002;402(1):71-78. DOI: 10.1016/S0040-6090(01)01667-4

24. Agashe C, Major SS. Effect of F, Cl and Br doping on electrical properties of sprayed $\mathrm{Sn}_{2}$ films. Journal of Materials Science Letters. 1995;15(6):497-499. DOI: 10.1007/BF00275412

25. Russo B, Cao GZ. Fabrication and characterization of fluorinedoped thin oxide thin films and nanorod arrays via spray pyrolysis. Applied Physics A. 2008;90:311-315.

26. Morris GC, McElnea AE. Fluorine doped tin oxide films from spray pyrolysis of stannous fluoride solutions. Applied Surface Science. 1996;92:167-170. doi:10.1016/0169-4332(95)00224-3

27. Ngamsinlapasathian S, Sreethawong T, Suzuki Y, Yoshikawa S. Doubled layered ITO/SnO2 conducting glass for substrate of dye-sensitized solar cells. Solar Energy Materials and Solar Cells. 2006;90(14):2129-2140. doi:10.1016/j.solmat.2005.12.005

28. Helander MG, Greiner MT, Wang Z B, Tang WM, Lu Z H. Work function of fluorine doped tin oxide. Journal of Vacuum Science \& Technology A. 2011;29(1):011019-1. http://dx.doi. org/10.1116/1.3525641

29. Iwase M, Oku T, Suzuki A, Akiyama T, Tokumitsu K, Yamada M, Nakamura M. Fabrication and characterization of poly[diphenylsilane]-based solar cells. Journal of Physics: Conference Series. 2012;352:012018.

30. Ikhmayies SJ, Ahmad-Bitar RN. Using I. V characteristics to investigate selected contacts for $\mathrm{SnO}_{2}: \mathrm{F}$ thin films. Journal of Semiconductors. 2012;33(8):083001-1.

31. Bergveld P. Thirty years of ISFETOLOGY. What happened in the past 30 years and what may happen in the next 30 years. Sensors and Actuators B. 2003;88(1):1-20. doi:10.1016/S09254005(02)00301-5

32. Chi L-L, Chou J-C, Chung W-Y, Sun T-P, Hsiung S-K. Study on extended gate field effect transistor with tin oxide sensing membrane. Materials Chemistry and Physics. 2000;63(1):1923. doi:10.1016/S0254-0584(99)00184-4
33. Chiu Y-S, Tseng C-Y, Lee C-T. Nanostructured EGFET pH sensors with surfacepassivated $\mathrm{ZnO}$ thin-film and nanorod array. IEEE Sensors Journal. 2012;12(5):930935. DOI:10.1109/ JSEN.2011.2162317

34. Yang X. Development of functional interfaces for sensing applications [thesis]. Auburn, Alabama: Auburn University; 2013.

35. Yates DE, Levine S, Healy TW. Site-binding model of the electrical double layer at the oxide/water interface. Journal of the Chemical Society. 1974;70:1807-1812. DOI: 10.1039/ F19747001807

36. Zhang Y, Arugula MA, Kirsch JS, Yang X, Olsen E, Simonian AL. Layer-by-layer assembled carbon nanotube-acetylcholinesterase/ biopolymer renewable interfaces: SPR and electrochemical characterization. Langmuir. 2015;31(4):1462-1468. DOI: 10.1021/la503474w

37. Kirsch JS, Yang X, Simonian AL. Layer-by-layer catalytic interface for electrochemical detection of multiple substrates featuring bio-functionalized carbon nanotubes. ECS Transactions. 2013;50(12):345-355.

38. Naimi SE, Hajji B, Humenyuk I, Launay J, Temple-Boyer P. Temperature influence on $\mathrm{pH}$-ISFET sensor operating in weak and moderate inversion regime: Model and circuitry. Sensors and Actuators: B. 2014;202:1019-1027. doi:10.1016/j. snb.2014.06.008

39. Vlekkerty HV, Bousse L, Rooij NF. The Temperature dependence of the surface potential at the A12O3/electrolyte interface. Journal of Colloid and Interface Science. 1988;122(2):336346. doi:10.1016/0021-9797(88)90369-4

40. Houchin MR, Warren LJ. Surface titrations and electrokinetic measurements on stannic oxide suspensions. Journal of Cooloid and Interface Science. 1984;100(1):278-287. doi:10.1016/00219797(84)90435-1

41. Houchin MR. Determination of surface charge at the tapiolite $\left(\mathrm{FeTa}_{2} \mathrm{O}_{6}\right) /$ water interface. Colloids and Surgafes A. 1985;13:125136.

42. Morrow R, McKenzie DR. The time-dependent development of electric double-layers in pure water at metal electrodes: the effect of an applied voltage on the local $\mathrm{pH}$. Proceedings of Royal Society. 2013;468: DOI: 10.1098/rspa.2011.0323

43. Bergveld P. ISFET, theory and practice. Presented at: IEEE Sensor Conference Toronto; 2004.

44. Jimenez RS, Bosco SM, Carvalho WA. Heavy metals removal from wastewater by the natural zeolite scolecite - temperature and $\mathrm{pH}$ influence in single-metal solutions. Quimica Nova. 2004;27(5):734738. http://dx.doi.org/10.1590/S010040422004000500011 